CASE REPORTS

\title{
Successful Treatment of Cerebral Aspergillosis in a Patient with Acquired Immune Deficiency Syndrome

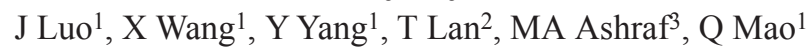

\begin{abstract}
We report a case of a patient with AIDS and a brain abscess caused by aspergillus, who underwent neurosurgical excision of the lesion and received subsequent therapy with voriconazole. The patient suffered from intracranial hypertension and visual disorders.
\end{abstract}

Keywords: AIDS, aspergillosis, central nervous system, surgery, voriconazole

\section{Tratamiento Exitoso de la Aspergilosis Cerebral en un Paciente con Síndrome de Inmunodeficiencia Adquirida

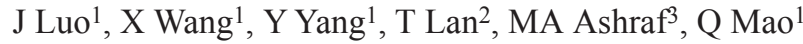

\begin{abstract}
RESUMEN
Reportamos el caso de un paciente con SIDA y un absceso del cerebro causado por aspergillus. El paciente experimentó extirpación neuroquirúrgica de la lesión, y recibió posteriormente tratamiento con voriconazol. Padecía de hipertensión intracraneal y trastornos visuales.
\end{abstract}

Palabras claves: SIDA, aspergilosis, sistema nervioso central, cirugía, voriconazol

West Indian Med J 2015; 64 (5): 540

\section{INTRODUCTION}

Opportunistic fungal infection is common in cases of superinfection, and is often a consequence of immunocompromise. For example, it is well recognized that patients with human immunodeficiency virus (HIV) infection are at a high risk for opportunistic infection and malignancy. Fungal infections with other organisms have also been reported to complicate HIV infection, most commonly Candida albicans, while Aspergillus infection is considered rare. For Aspergillus infection, about $95 \%$ of cases are caused by Aspergillus fumigatus, Asporgillus or Aspergillus niger, which most commonly colo-

From: ${ }^{1}$ Department of Neurosurgery, ${ }^{2}$ Department of Pathology, West China Hospital, Sichuan University, 37 Guo Xue Xiang, Wuhou District, Chengdu 610041, China and ${ }^{3}$ University Malaysia Sabah, Kota Kinabalu, Sabah, Malaysia.

Correspondence: Q Mao, Department of Neurosurgery, West China Hospital, Sichuan University, 37 Guo Xue Xiang, Wuhou District, Chengdu 610041, China. E-mail: qingmao3000@163.com nize the lungs, with the central nervous system (CNS) the second most common focus of infection (1).

We describe the case of a patient with HIV infection and acquired immune deficiency syndrome (AIDS) complicated by CNS Aspergillus superinfection. After excision of the lesion and subsequent treatment with voriconazole, the patient made an uneventful recovery without evidence of relapse over the ensuing 12 months.

\section{CASE REPORT}

A 43-year old Chinese man was hospitalized with a one-month history of dizziness, intermittent bilateral parietal and occipital headache of moderate severity associated with nausea and vomiting, and unilateral blurred vision affecting the left eye. He had been diagnosed with AIDS one year previously and had been taking antiretroviral therapy irregularly. On admission to hospital, neurologic examination revealed reduced power in the right limbs and trunk, but no other focal deficit. 
Subsequent magnetic resonance imaging (MRI) of the head showed a ring-enhancing space-occupying lesion in the left occipital lobe surrounded by extensive cerebral oedema, resulting in pressure on the left lateral ventricle (Fig. 1). Empiric treatment for decreasing intracranial pressure was initiated with mannitol $500 \mathrm{~mL} /$ day and methylprednisolone 80 $\mathrm{mg}$ /day by intravenous infusion. Despite treatment, his vision remained blurred and it became evident that his visual fields were abnormal. Consequently, we elected to excise the lesion under general anaesthesia 10 days after admission.
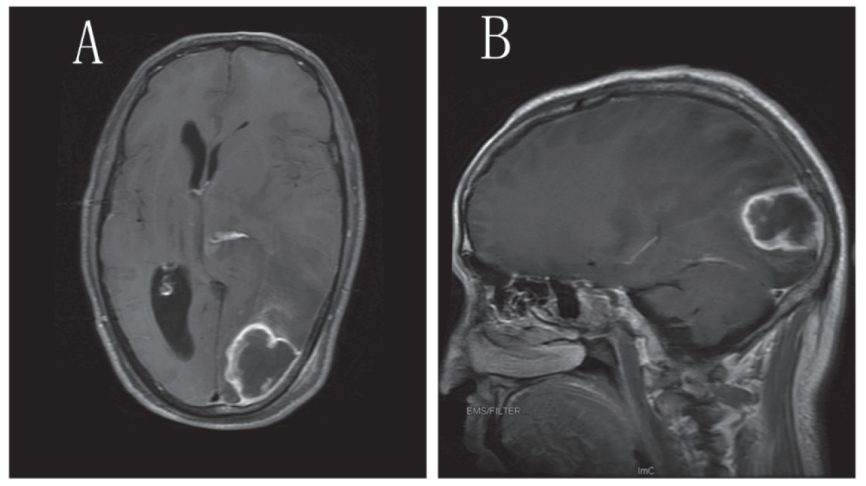

Fig. 1: Magnetic resonance imaging (MRI) of head. A: T1WI with gadolinium contrast axial plane; B: T1WI with gadolinium contrast sagittal plane.

At surgery, the dura was found to be incomplete but firm and thick-walled. After resection of the dura, inflamed but well-circumscribed cerebral tissue and copious white seropurulent fluid was found. The operation was uneventful. The biopsy samples later showed inflammation and extensive infection with Aspergillus on haematoxylin and eosin staining (Fig. 2).

After surgery, the patient was commenced on voriconazole $600 \mathrm{mg} / \mathrm{day}$ by intravenous infusion as antifungal therapy. The headache and neurologic deficits had resolved by the third postoperative day, and the patient was transferred to his local hospital for further rehabilitation 20 days after admission.
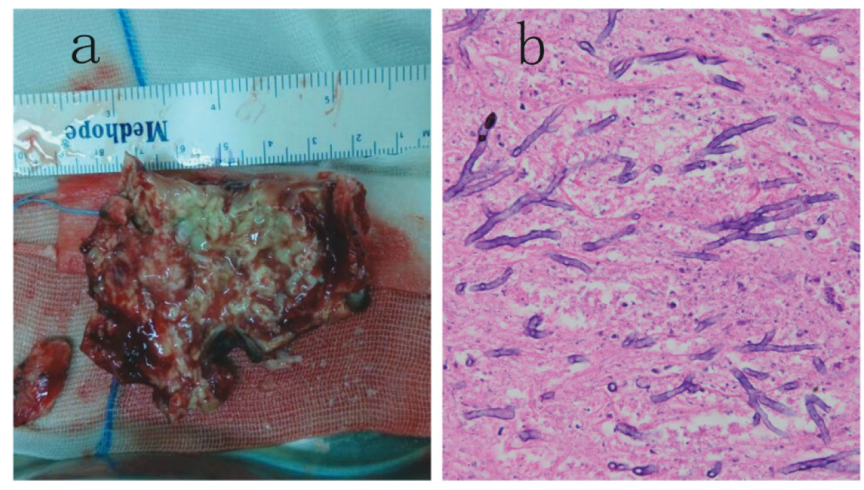

Fig. 2: (a) Macroscopic view of the lesion during operation; (b) haematoxylin and eosin staining of tissue sections (magnification $\times 400$ ).

\section{DISCUSSION}

Cases of Aspergillus superinfection in the CNS are rare and such cases complicated by AIDS are even rarer. Besides, there is still no agreed standard of diagnosis and treatment. Compared with reported cases, our case shares some similarities in symptoms, auxiliary examinations and magnetic resonance images (Table). The main difference lies in the treatment method: we excised the lesion by performing a craniotomy followed by antifungal therapy.

In most cases, the lungs are affected. It has previously been reported that the most common focus of infection is invasive pulmonary aspergillosis (in $80-90 \%$ of cases), of which $10-25 \%$ might spread to involve the CNS (2). There are no guidelines to assist the diagnosis of cerebral aspergillosis. Patients may report symptoms or exhibit signs of raised intracranial pressure, impaired consciousness, motor dysfunction or meningeal irritation. Brain imaging with computed tomography (CT) or MRI can be used to confirm the presence of a space-occupying lesion. In most cases (3-5), additional investigations such as cerebrospinal fluid (CSF) routine, biochemistry and CD4-positive lymphocyte count are required. If none of these investigations confirms the presence of an intracranial opportunistic fungal infection, or are unable to dis-

Table: Comparative characteristics of published cases and index case

\begin{tabular}{|c|c|c|c|c|c|c|}
\hline Case & Year & Location & $\begin{array}{l}\text { Size } \\
(\mathrm{cm})\end{array}$ & Treatment* & Recovery & Survival time ${ }^{\#}$ \\
\hline Khoury (3) & 1997 & $\begin{array}{l}\text { Parietal } \\
\text { lobe }\end{array}$ & $3 \times 2$ & (1) & 1 & 3-4 months \\
\hline Vidal (1) & 2005 & $\begin{array}{l}\text { Parietal } \\
\text { lobe }\end{array}$ & / & (1) & 1 & 3 months \\
\hline Hidron (4) & 2009 & $\begin{array}{l}\text { Frontal } \\
\text { lobe }\end{array}$ & $2.6 \times 2.0$ & (1) (2) & I & 10 months \\
\hline González (5) & 2012 & $\begin{array}{l}\text { Multiple } \\
\text { parts }\end{array}$ & / & (1) & NO & 5 days \\
\hline Segundo (2) & 2014 & $\begin{array}{l}\text { Sphenoid } \\
\text { sinus }\end{array}$ & / & (1) (2) & YES & l \\
\hline Index case & 2014 & $\begin{array}{l}\text { Occipital } \\
\text { lobe }\end{array}$ & $4.1 \times 2.9$ & (1) (2) & YES & $\begin{array}{l}\text { More than } 12 \\
\text { months }\end{array}$ \\
\hline
\end{tabular}

*: (1) - antifungal therapy:(2) - surgery; \#: the time from the patient's hospitalization to death 
tinguish infection from a glioma or metastatic tumour, histopathological examination of tissue obtained from brain biopsy or craniotomy is crucial for diagnosis, to inform clinical decisions about treatment and to indicate likely prognosis. Most cases of CNS fungal infection are confirmed by brain biopsy, but this approach carries a risk of a false-negative result. Accurate biopsy and acquisition of sufficient pathological specimens are essential. Surgeons may be reluctant to undertake procedures on patients with AIDS for fear of becoming infected themselves should they sustain an intra-operative injury. In this case, we elected to undertake surgery as our hospital has the capability to manage such complex cases, and the patient and his relatives consented to this approach. Surgery not only afforded the opportunity to address the patient's symptoms in the immediate term, but also provided biopsy material that guided further management to ensure a long-term, uneventful recovery. Our strategy was consistent with that of Nabika and colleagues (6), who adopted an invasive approach to treating a patient with HIV infection and an aspergilloma in the prepontine cistern, and underlines the importance of diagnosing and treating cerebral aspergillosis promptly. As cases are rare, there is little evidence to guide clinical decision-making when treating these life-threatening superinfections, with a particular deficit of outcome data. In addition, Liu et al (7) summarized that the superiority of voriconazole as initial therapy for aspergillosis infection in terms of response rate, survival rate and safety has now been demonstrated in a large randomized study. Our patient treated with surgery combined with voriconazole showed favourable outcomes.

\section{CONCLUSION}

We achieved a favourable outcome in a patient with life-threatening CNS aspergillosis in the context of acquired immunodeficiency using a combination of surgery, medical control of intracranial pressure and an antifungal drug. In this case, the decision to undertake surgery was finely balanced, but the evolving situation soon favoured excision of the space-occupying lesion. Without more evidence, these cases will remain challenging, but their rarity means that there is little opportunity to conduct clinical trials in all but the largest centres.

\section{REFERENCES}

1. Vidal JE, Dauar RF, Melhem MS, Szeszs W, Pukinskas SR, Coelho JF et al. Cerebral aspergillosis due to Aspergillus fumigatus in AIDS patient: first culture-proven case reported in Brazil. Rev Inst Med Trop Sao Paulo 2005; 47: 161-5.

2. Segundo JB, da Silva MA, Filho WE, Nascimento AC, Vidal FC, Bezerra GF et al. Cerebral aspergillosis in a patient with leprosy and diabetes: a case report. BMC Res Notes 2014; 7: 689.

3. Khoury H, Adkins D, Miller G, Goodnough L, Brown R, DiPersio J. Resolution of invasive central nervous system aspergillosis in a transplant recipient. Bone Marrow Transplant 1997; 20: 179-80.

4. Hidron AI, Gongora MC, Anderson AM, Diazgranados CA. Prolonged survival of a patient with AIDS and central nervous system aspergillosis. Med Mycol 2009; 47: 327-30.

5. González-Duarte A, Saniger M, Arispe-Angulo K, Gamboa-Dominguez A, García-Ramos G. 47 year-old man with HIV infection and hemiplegia. Brain Pathol 2012; 22: 567-70.

6. Nabika S, Kiya K, Satoh H, Mizoue T, Araki H, Oshita J. Local administration of amphotericin B against aspergilloma in the prepontine cistern-case report. Neurol Med Chir (Tokyo) 2007; 47: 89-92.

7. Liu W, Chen H, Cai B, Li G, You C, Li H. Successful treatment of sellar aspergillus abscess. J Clin Neurosci 2010; 17: 1587-9. 